\title{
"100 Years of University Nursing Education": The Significance of a Baccalaureate Nursing Degree and Its Public Health Origins for Nursing Now
}

\author{
Susan M. Duncan \\ University of Victoria, susanmduncan@uvic.ca \\ Margaret R. Scaia \\ University of Victoria, mrscaia@uvic.ca \\ Geertje Boschma \\ University of British Columbia, geertje.boschma@ubc.ca
}

Follow this and additional works at: https://qane-afi.casn.ca/journal

Part of the Education Commons, History Commons, and the Public Health and Community Nursing Commons

\section{Recommended Citation}

Duncan, Susan M.; Scaia, Margaret R.; and Boschma, Geertje (2020) "'100 Years of University Nursing Education": The Significance of a Baccalaureate Nursing Degree and Its Public Health Origins for Nursing Now," Quality Advancement in Nursing Education - Avancées en formation infirmière: Vol. 6: Iss. 2, Article 8.

DOI: https://doi.org/10.17483/2368-6669.1248

This Article is brought to you for free and open access by Quality Advancement in Nursing Education - Avancées en formation infirmière. It has been accepted for inclusion in Quality Advancement in Nursing Education - Avancées en formation infirmière by an authorized editor of Quality Advancement in Nursing Education - Avancées en formation infirmière. 
Why dwell on the past? For this reason, we study the future in light of the past. We just judge of what is good in the past and see if by any means we may still hold to it, reaching out at the same time for the broader opportunities of the future. (Ethel Johns, cited in Street, 1973, pp. 122-123)

The University of British Columbia (UBC) School of Nursing's centennial celebration of university nursing education in Canada in 2019 prompts us to critically reflect on the meaning of baccalaureate education and its origins in a public health mandate today. The history of the first baccalaureate program at UBC has been well documented by Street (1973) and Zilm and Warbinek (1994). Ethel Johns, the School's first director and influential Canadian nurse leader, was recently acknowledged as a person of national historic significance by the Canadian government (Parks Canada, 2009). We are indeed indebted to the vision of leaders like Ethel Johns, and many inspirational nursing leaders with her, who embarked on the "experiment" of university nursing education to establish nursing degree programs in Canadian universities (Johns, 1936). The road was neither easy nor predictable. In today's context, it seems timely to reflect on the past vision that led to the birth of university nursing education in Canada, and with it, a significant public health agenda. The long climb to university education over the past century with conflicting layers of tensions and paradoxes inherent in the nursing profession's self-determination as an academic discipline seems at a significant juncture in that journey today.

There are three main themes to be explored in the 100-year history of university nursing education in Canada, and the issues and debates surrounding the question: University nursing education: Why then and why not now? ${ }^{1}$

Johns's central commitment was to advance nursing knowledge, to enhance leadership capacity, and to keep nursing and nurses committed to a social mandate of just and equitable care (Grypma, 2003; Street, 1973; Young, 2005). Three themes in her vision are particularly relevant today: (1) knowledge required for nursing practice; (2) leadership for the profession and the discipline, including relationships between individuals and organizations; and (3) social accountability (how the profession anticipates and positions itself relative to health needs and aspirations of social justice). The challenge we offer in this paper is to examine the question: Has the vision of leaders like Ethel Johns stood the test of time?

In this paper, we touch on these three points and reflect on some markers in the history of nursing education as enduring standpoints on which to gauge current and future states of nursing. Persistently, over the last century, the value of sustaining university-level education as the requirement for entry-level registered nurses has been questioned (Mansell, 2004). Through this discussion, we intend to provoke awareness of some pressing critical issues in our professionand discipline - arguing that we may take guidance from some of the critical contributions of Canadian nursing education over the past century that seem to have particular relevance for understanding nursing in 2020. Moreover, we explore questions pervasive in the history of academic nursing education through the lens of Ethel Johns and other leaders in nursing.

Further, we ask questions of how sociopolitical contexts influenced development of these visions and, most importantly, how the enduring themes of knowledge, leadership and social accountability, relate to the vision of nursing education today. To address these questions, we will reflect simultaneously on past and present, in particular we observe the similarities between the

\footnotetext{
${ }^{1}$ A first draft of this paper was presented by Susan Duncan at the 2019 Nursing History Symposium at UBC, Vancouver, March 14, 2019, at the occasion of the centennial celebration of the UBC-V School of Nursing.
} 
call for nursing leadership in response to the influenza pandemic of 1918 and the deeply felt need for nursing leadership and capacity in response to the SARS-CoV-2 (COVID-19) pandemic of 2020. The goal to expand the capacity of public health nursing in response to the health crises and epidemics experienced then was the original impetus for a university education at UBC and other universities, such as Dalhousie University, McGill University, the University of Toronto, the University of Western Ontario, the University of Alberta, and the University of Montreal (Tunis, 1966, pp. 120-122). The strong argument nursing leaders voiced in support of a baccalaureate degree then may inspire a look at the way the value of a Bachelor of Science in Nursing (BSN) preparation is upheld by the profession and society today. Therefore, our inquiry proceeds with how Grypma (2017) describes "history as a safe place to explore sensitive topics, including "skeletons in the closet" (p. 4), that persist today.

\section{Background: The Inspiring Vision of University Nursing Education}

How did Johns's early vision of the need for university nursing programs resonate with what society needed from nursing? What were the health needs at the time and the contextual influences that shaped nursing? Johns envisioned that society needed nurses to lead change in health systems for the promotion of health, a vision held by provincial and national nursing organizations and supported by key medical leaders in the province at the time. Notably, in a signature address at the Vancouver General Hospital in 1919, she reiterated her view that nurses needed the "breadth and depth of preparation" [at the university level] to fulfill its social mandate of addressing people's health needs across the full life cycle, "from the cradle to the grave" (Johns, 1919, as cited in Street, 1973, p. 124). Reflecting on the forces and people who inspired the move to university education for nurses at UBC, in later years referred to by Ethel Johns (1936) as "the experiment," one can see how these early leaders held a broad view of health and community service, a role for which women would be best equipped by means of a university education in nursing. In fact, in their plea for a central focus in nursing on public and community health, what we would consider determinants of health today, Johns and others also emphasized the central role of nurses in the health care system, working in collaboration with patients, their families, physicians, other skilled care providers and lay caregivers, or other community members (McPherson, 1997). Preparing leaders in community nursing, particularly as public health nurses (PHNs), they considered the obvious mandate of university nursing education in this broader context.

In addition to the emerging mandate of public health, the hospital standardization movement was another contextual influence stimulating the quest for university nursing education. The establishment of a nursing degree at UBC occurred in close collaboration with medical leaders keen to enhance hospital reform by means of standardization and introduction of so-called scientific management (Toman, 2005). Leading physicians of Vancouver General Hospital $(\mathrm{VGH})$, then one of the largest, and most ambitious, fast-growing public hospitals in Canada, joined the call for university nursing education for that reason. Malcolm MacEachern, the medical superintendent of $\mathrm{VGH}$, and, as president of the American Hospital Association, a physician and leader in the hospital standardization movement, was keen to involve nurses in scientific management of hospital administration. University-based preparation for nurses would support that trend, and he was well aware of the way nursing had taken this direction in the United States. He was a significant reformer of hospital quality, in which nursing education and standards of practice were key elements (Zilm \& Warbinek, 1994). Street (1973) surmises that MacEachern likely met and was influenced by nursing leader Isobel Stewart, a Canadian and then-professor in 
the Department of Nursing at Teachers College, Columbia University, ${ }^{2}$ when "she addressed the convention of the BC Hospital Association of which the founder, Superintendent MacEachern was president" (p. 119). Further support of nursing education reform came from physician and public health leader Henry Esson Young, secretary of the British Columbia (BC) Provincial Board of Health which already had started to appoint nurses to establish vaccination programs, assist with medical inspection, and help reduce communicable diseases and high infant mortality. Esson Young called for nurses to be prepared for the field of public health.

The new university in British Columbia, only established in 1915, "as the last provincial university founded in Canada," seemed to have been flexible and open to new endeavours, particularly to support public health, in ways its well established counterparts in the core of the Empire were not (Stewart, 1990, pp. XI, 32). Further, we observe how a web of relationships between nursing, university, and health leaders came together to support a vision of nursing education with a mission to prepare nurses for public health, teaching, and leadership roles.

\section{Public Health Nursing}

The influenza pandemic of 1918-1920 drew attention to the contributions of PHNs and the need to expand education in public health nursing to more effectively respond to the threat of contagious diseases. Nurses worked to project a vision of their role within emerging departments of public health and in so doing were responding to challenges of preventing illnesses in young children and the importance of nutrition and communicable diseases such as tuberculosis (TB). With grant support of the Canadian Red Cross, the universities listed above all established university programs in public health and nursing education around 1920 (Tunis, 1966). In particular, the Canadian Red Cross proposed in 1918 to sponsor educational programs in public health in recognition of the urgent need for PHNs, which aligned with the effort to have these programs integrated in the university along with the plea for degree programs.

Zilm and Warbinek (1994) describe the first PHN specialty roles in the areas of school health and TB tracing and indeed point out how there was recognition that nurses with additional education could make a difference to the health of families and communities. Nursing leaders in partnership with others advocated for this education and made it happen by collaborating with national and local non-governmental organizations, non-nurse leaders, physicians, and leaders within the women's movement. Advancing public health resources for women and families to address the high infant and mortality rates was a prime interest within the women's movement (Brush et al., 1999).

Just prior to her appointment at UBC, Johns had a central role in promoting public welfare as a member of the Manitoba Public Welfare Commission (1917-1919), one of the first nurses to be appointed to such a committee. Here, she influenced nursing and health policy agendas that

\footnotetext{
${ }^{2}$ A historical note of interest: Over the past century, Teachers College, Columbia University has figured prominently in the advanced education profile of Canadian nurses. The recent passing of Dr. Shirley Stinson, celebrated Canadian nursing leader, on June 4, 2020, brings this to light; she was the first nurse in western Canada to receive a doctoral degree, her EdD, from Teachers College in 1969. The first author of this paper was a student in Dr. Stinson's undergraduate nursing course on nursing trends in 1977 at the University of Alberta, where Dr. Stinson inspired her inquiry into the life and work of Ethel Johns. The inquiry included a conversation with biographer Margaret Street, facilitated by Dr. Stinson. Her remarkable ability to inspire students has led to an ongoing value of nursing historical inquiry and leadership to the current publication. We received notice that this paper was accepted on June 4, the day of Dr. Shirley Stinson's passing. This article is dedicated to the memory of Dr. Shirley Stinson as an inspiring teacher of nursing history.
} 
included hospital inspections, improved hospital nursing education, and advocated for university nursing education (Street, 1973). Outcomes included a commitment to action inspired by the view that PHNs, in particular, along with nurse educators required a university nursing education (Zilm \& Warbinek, 1994).

In World War I and the years immediately following there was attention to the significance of leadership in public health nursing in Canada. For example, the Canadian National Association of Trained Nurses (CNATN) established a PHN section in 1920, and the PHNs contributed significant writings on public health matters to The Canadian Nurse and the Canadian Public Health Journal, later renamed the Canadian Journal of Public Health. As the number of nurses with university degrees and diplomas in public health nursing grew, they successfully organized themselves into an independent body for public health nursing, which further stimulated engagement of nurses in public health policy (Emory, 1953). Similar to Ethel Johns, public health nurses obtained roles on governmental committees and engaged with larger public health agendas to meet public health needs.

In these early days, one sees the impact of this broad vision on the sociopolitical dimensions of health, and the abilities to organize programs and systems of care, as well as attend to immediate health needs of individuals and families in homes, clinics, and schools (Duncan, Leipert, \& Mill, 1999). Also significant and in contrast to today, the PHN services were universal-accessible to populations regardless of level of risk; a phenomenon that was essentially unchanged in Canada until the neo-liberal shift in public health policy of the 1990s (Falk-Rafael, 1999). In recent decades, the focus of public health has further shifted to programs and population-focused interventions in public health organizations and government, while funding of programs has not increased. Public health nursing in 2020 is no longer what it was, following decades of erosion of nursing priorities, programs, leadership, and continuity of connections between nurses and communities (Kirk, 2020; Sanders et al., 2019).

The 2020 pandemic may well be surfacing the loss of emphasis on public health nursing contributions as schools of nursing struggle to locate practicum opportunities for nurses in acute care, while not fully appreciating the opportunities and promise of community and public health nursing roles as essential grounds of preparation. This stands in contradiction to the conception of leadership and breadth of vision for health and health promotion inherent in the original vision of the baccalaureate university nursing degree.

\section{Knowledge: The First Nursing Curriculum}

A strong vision and appreciation for the breadth and depth of knowledge required to prepare nurses for public health nursing and for teaching and administrative roles guided the development of the first university course curricula. In addition, there was a surge in nursing leadership because public health was an emerging area of prestige for women as educated, skilled, and valued professionals (Scaia, 2017). Careers in nursing and public health formed an area of advancement for women, contributing not only to the application of science in health but also to advocacy for better school and vaccination programs, ultimately seeking to improve the health of the population (McKay, 2009).

The first university curriculum was developed to prepare teachers and public health nurses with courses and foci in community health that remain in nursing programs today (Duncan, 2016). All students received a breadth and depth of preparation in psychology, sociology, and science and then chose a focus in pedagogy or public health nursing. Typical topics in public health nursing 
included health teaching, school health, control of communicable diseases, social work principles, and administrative and organizational principles.

As much as access to university education was questioned for women, so was the value of higher education and knowledge required for practising nurses generally. In this regard, Ethel Johns, in her address to the CNATN Convention, July 1920, already articulated the tensions between requirements for highly knowledgeable and skilled nursing care and what she described as more routine nursing duties in the care of people in the home provided by private duty nurses: "Physicians and the public accuse us of educating nurses away from nursing and rendering them unwilling to perform ordinary nursing duties. I leave it up to you to say whether or not there is some truth in this accusation. They urge us to lower our standards, to give shorter courses, to do something to get nursing attendance for people who need it" (cited in Street, 1973, p. 135).

Here, Johns is referring to the specific context of private duty nursing (which was only available to those who could afford to pay for it) and the nature of tensions inherent in defining the standards and preparation for professional nursing practice. This ambiguity had to be taken up persistently in the decades to come, when concerns about the role and education of nurses continued to be an issue of national concern.

\section{Notable Education Policy Reports}

A first national report on the matter of standards of nursing education was an extensive survey on nursing education conjointly issued by the Canadian Nurses Association and the Canadian Medical Association in the early 1930s. George Weir, professor of education at UBC, was commissioned to undertake the study and published the extensive Survey of Nursing Education in Canada in 1932. The question of the standard of nursing education was a clear focus in the report. Weir affirmed the need for university education and a high standard of education decoupled from the gendered traditions of nursing as an act of higher calling or service to the public. Weir also questioned if two levels of nursing- "practical and professional"-was confusing to the public (p. 51). Although Weir's endorsement of formal nursing education decoupled from the almost exclusively service orientation that dominated across Canada sent a clear message, during the Depression years the issue was not widely taken up. It was not until about a decade later, for example, that, under the directorship of Kathleen Russell, the first integrated baccalaureate program was initiated at the University of Toronto in 1942, building upon the university program in public health nursing the university had held since 1926 (Boschma, 2005). From that time onwards, similar nursing degree programs began to be established at universities across the country, although the number of university graduates remained small compared to the overall number of nurses, the majority of whom graduated from the hospital-based programs.

Helen Mussallem's (1960) Spotlight on Nursing Education formed a next influential study on nursing education. It was undertaken to provide input to the survey of the Royal Commission on Health Services in the early 1960s to address among others the severe shortages in qualified health care personnel (Boschma, 2005). As the former director of the Vancouver General Hospital School of Nursing, seconded to conduct the study, and appointed executive director of the Canadian Nurses Association in 1962, Mussallem looked at the status of hospital schools of nursing and recommended closing of smaller schools based on the conclusion that smaller schools did not adequately prepare nurses according to established standards (Zilm \& Warbinek, 1994). The ideal that all nurses should be educated at universities, however, was also recognized to be 
unrealistic considering where nursing was at, at that time. Her report supported the view that nurses should receive the same level of education as other health professionals, and it was recommended that baccalaureate nursing should be expanded, but the hospital-based system could not yet be abolished considering the need for nurses in a time of severe shortage. The Royal Commission on Health Services, also known as the Hall Report (1964) recommended universal health care in Canada. It also recommended two levels of education for nurses: academic and so-called technical nursing to address the rapidly increasing need for nurses. In reference to nursing, Hall concluded: "In light of our knowledge of and established practice in the education of all other 14 professions, the apprenticeship-type system by which the majority of nurses are now solely trained clearly requires re-examination" (p. 63).

What had to be negotiated within the larger health care system in the 1960s and through the 1970s and 1980s was a way to balance demand for (higher) nursing education with the persistent pressure to meet workforce demands. Increased specialization and a rapidly expanding hospital-based health care system (which expanded without much recognition of the complementary need for high-quality home and community care) required more and better prepared nurses even though the attention was mostly drawn to such need within the hospital context. It compelled nurse leaders to advocate for the baccalaureate degree as the entry-level registered nursing education also known as the Baccalaureate as Entry to Practice campaign by the year 2000 (Mansell, 2004). It was seen as a necessary step to support nurses' quest to have a voice in health care decision making (Boschma, 2005).

Simultaneously, pressures of practice and continuous shortages in meeting workforce demands made hospital administrators and governmental policymakers wary of increasing entrylevel nursing educational standards, whether it was from the viewpoint of costs of higher pay or worry over too much nursing autonomy, a standpoint typically also supported by a medical profession historically granted much control over nursing education. Heated debate and professional tension persisted, not only over an alleged dualism between practical and theoretical nursing but also between the various professional groups and levels of nursing education within the profession that emerged in response to the larger health care system pressures nevertheless (Twohig, 2018). Registered nurses also had a key role in developing and overseeing the education and expansion of licensed practical nurses or registered practical nurses or nurse assistants; the quest for a unified entry level to professional nursing practice never consolidated (Caputo, 2016; Twohig, 2018). On the one hand, there was a strong discourse within the profession to free itself from medical domination and take control over nursing education by the profession itself. The drive for autonomy fuelled ideals of professionalization and educational advancement. Nurses and policymakers alike also recognized the ineffectiveness of a largely student nursing workforce turning over every three years, draining expertise and much needed leadership out of the health care system in the face of continually increasing demand for nurses. This was a key point in both the Weir and Mussallem reports and fuelled the quest for nursing education reform. On the other hand, there was recognition of the need for internal differentiation within the nursing profession to meet workforce demands, and various levels of nursing education emerged, including nurse assistants, care aides, licensed practical nurses, registered nurses, and specialized advanced practice nurses (Twohig, 2018). Still, a unified voice over the educational requirements of this increasingly diversifying nursing work force was hard to reach, and nursing remained a "divided house" (Baer, 1984). In light of such pressures, the argument for higher university nursing education to support nursing participation, if not leadership, in important matters of practice and 
policy development, as well as research and knowledge construction in just and affordable care, remained a hard to negotiate topic, within and outside of the profession.

To complicate matters, once degree programs in nursing expanded, a perspective on the importance of advanced and basic preparation in specialty areas, such as public health, community nursing and the expanding field of primary health care, remained scattered at best. As public health service and government funded health insurance materialized in the 1960s and 1970s, acknowledgement of public support for public health, home care, and primary health care found little acknowledgement in the publicly funded health care system. The main focus in health policy during the 1950s and 1960s centered on hospital-based health care. Hence, publicly funded nursing education, including the development of baccalaureate education, also developed foremost to meet hospital-based care demands and specializations. The impact of these historical developments is still apparent today.

In the early 1980s, the Canadian Association of University Schools of Nursing jointly with the Canadian Nurses Association further shifted the discourse over university nursing education to the standpoint that a baccalaureate degree should become the entry-to-practice requirement for registered nurses at point of care (Canadian Association of Schools of Nursing [CASN], 2012). In the process, the role of registered nurses became more and more tied to their position in an increasingly hospital-based health care system. In recent decades, patient outcome research has begun to establish the value of a higher complement of BSN-prepared nursing workforce in preventing hospital-based mortality rates (Aiken, 2014; Aiken et al., 2017) and to emphasize the importance of quality and quantity in staffing models (Needleman et al., 2020). However, this research has not been extended to other care settings and does not yet focus on populations in great need of an expanded and transformed RN role, now exposed in the context of COVID-19, including public health, long term care, home care, and mental health.

By 1989, all provinces except Quebec had adopted the BSN as the entry-to-practice requirement, resulting in university and college partnerships to make it happen. This period of connection to the university and other institutions solidified a commitment to university-level education; mentorship within and between organizations was significant in establishing academic foundations (Zawaduk et al., 2014). Today, the CASN (2015) National Nursing Education Framework is a comprehensive statement on the domains of nursing education-BSN to master's to $\mathrm{PhD}$. The profession indeed has made great strides in graduate programs and research agendas, yet there are persistent tensions in sustaining a depth and breadth of preparation in undergraduate nursing programs and fulfilling the mandate of preparing nurses for diverse roles and settings across the continuum of care and health promotion.

Today, we argue that we are less vocal in advocating for the undergraduate qualification of a BSN. Instead, we observe a tendency toward a dominant discourse of scope and harmonization of roles and standards across diploma and degree nursing programs and qualifications (British Columbia College of Nursing Professionals, 2020; Duncan \& Whyte, 2018; MacKinnon et al., 2018). This tendency, we also argue, has occurred without due attention to the knowledge domain of the discipline and the respect for differences in preparation and role identities among regulated nurses.

\section{Leaders Inspiring Leadership}

Relationships, advocacy, and vision characterize leadership styles of those who worked to advance nursing education and public health nursing over the past century. History inspires us to 
look at nursing collectivity as it was actualized in the past. Nurse historian Diane Hamilton (1994) highlights how "a thought collective," or community of nursing leaders, connected with the Henry Street Settlement in New York in the beginning of the 20th century, had a vision of nursing as a sisterhood with a core value of compassionate care of humanity without the need to frame such demands within a discourse of self-sacrifice that they felt had characterized organized religion. Relationships and connections-nationally and internationally and between nurse leaders in nursing organizations and government - were foundational to developing vision and power for advancements in education and public health. "Women's internationalism and friendships" were also significant as the League of Red Cross Societies sponsored a yearlong international public health course at Bedford College in London, England, with the participation of Canadian nurses who went on to hold leadership positions in nursing education, public health, administration, and professional organizations (Lapeyre \& Nelson, 2010, p. 35). In 1912, VGH's superintendent of nurses, Helen Randal, for example, was a key leader in forming a provincial nursing association, enabling British Columbia nurses to join the international movement, closely aligned with the women's movement, to organize and achieve nurse registration. Randal and other early leaders of the nursing profession were also keen to move a public health agenda and improve nursing education. As a result of these influences, UBC, then located on the grounds of the Vancouver General Hospital, agreed, in 1919, to open a nursing degree program within the Faculty of Applied Science.

Johns herself role-modelled such linkages with nurse leaders and nursing associations and she held impressive organizational ability. She led the profession in numerous roles, including as editor of The Canadian Nurse, as an influential and spirited writer; she led the development of the Canadian Association of Nursing Education; and she served as an executive leader of many nursing and public organizations. To acknowledge the visibility of her leadership prowess, the Rockefeller Foundation recruited her from her post as the first director of the UBC School of Nursing to lead international advancements in nursing education (Street, 1973). It is significant that through all of her professional achievements and advancements, she never lost her focus on the advocacy required for advancing and articulating the need for both nursing education and public health nursing roles.

Early public health leaders in Canada, such as Eunice Dyke, director of public health nursing of the Department of Health in Toronto, and others, led the formation of groups and organizations that advocated on behalf of education and public health nursing practice (Duncan et al., 1999). Other leaders on the global stage include Lyle Creelman who held the post of chief nursing officer in the World Health Organization (WHO), 1954-1968, and who was a strong advocate for public health nursing and academic education (Armstrong-Reid, 2014). The point here is that public health leaders were very involved in nursing associations of the day, assuming leadership positions of provincial and national organizations, and in government. Currently, one does not see positions specifically designated for public health nursing leadership in the health sector or government, such as the director of public health nursing held in previous eras. In fact, Canada, in 2020 - the International Year of the Nurse and Midwife-does not have a chief nursing officer despite international and national advocacy for this position (Grypma, 2019). These early influences within the government and the connectivity among nurses paved the way for significant influences on health programs and population needs. Notably, the essence of the WHO's declaration of the International Year of the Nurse and the Midwife is predicated on the need for advocacy and activism for health, in what was the original vision and tradition of public health nursing. 


\section{Social Accountability: Nursing's Role in a Public Health Mandate-Then, Now, and in the Future}

Although public health nursing emerged as an exemplar of nursing leadership and accountability for social change and with it the impetus for university-based education and the evolution of a body of knowledge for its practice, it may now be seen to be in peril. The current state of public health nursing in particular may well be the canary in the coal mine of what is happening to nursing and how nursing education for the practice of community health nursing is actualized. The COVID-19 pandemic in particular shines a spotlight on the PHN role and its diminishing visibility and presence over the past decades (Falk-Rafael, 1999). As we trace the path of the past century, PHN serves as the most striking contrast to what took place 100 years ago, when the knowledge and skill required of a PHN was the impetus for university nursing education.

As COVID-19 exposes public health and nursing in ways unseen this past century, media focuses on multiple reports and interviews with medical historians, public health physicians, and emergency physicians while nurses remain virtually invisible except when exposed in the neglect of patients, such as in the nursing home cases, or when heralded as heroes at the bedside; they are rarely seen as the knowledge holders or champions of public health reform. Exceptions of course exist, but these could benefit from more attention in the public media. Recent changes in governance and mandates of professional nursing associations have limited the resources available to support a collective voice and advocacy to address health care and public health issues. As we well know, there is a focused body of knowledge and skill needed to mount and maintain a significant PHN program to combat communicable disease among all age groups. Equally important is the public awareness that continual budget cuts and downgrading of basic nursing care and preventive services to the most minimal levels of service, pay, and educational preparation endangers people's health and safety. It also erodes the capacity and resources to respond to essential health needs or build supportive communities. Advocacy for care of seniors, their care providers, and those most vulnerable are foundational competencies in nursing education today and should be once again visible in PHN practice and education. Fulfilling advocacy roles requires support for nurses to bring voice to the care of those most vulnerable, where they have been silenced or absent in systems where nurses work. This significant advocacy work of nurses requires new conceptual models, and research initiatives are urgently needed to direct the development of the discipline and professional practice for 21st century health gains (Butterfield, 2017).

\section{Conclusion: The Imperative and the Inspiration}

We are at a critical point in needing to reaffirm the essence of academic preparation of the nursing workforce. In light of these realities, we may well question whether nursing is upholding the BSN as the essential preparation and standard level of education for the continued formation of a critical mass of nurses equipped to lead jointly with other health disciplines and communities to transform systems for diverse population needs. How might we use the past to inform these present issues and debates? COVID-19 may well be a teacher that sparks critical debate about the state of nursing education and the need to revision social accountability, knowledge, and depth of baccalaureate nursing educational preparation and its original mandate to prepare nurses for public health, leadership, and teaching roles; all remain as urgent priorities today.

To the question of nursing's social accountability in this century, What should society expect from public health nursing as an integrated component of baccalaureate degree programs? To answer, one must look to the social imperative with an eye to current and future transitions. 
Informing the imperative are the foundational declarations of our time: The United Nations 2030 Agenda for Sustainable Development (United Nations, 2015), the UN Declaration of the Rights of Indigenous Peoples (United Nations, 2007), and the Truth and Reconciliation Commission of Canada's Calls to Action (2015). These declarations represent the opportunity for nurses and nursing to renew a vision and commitment to deep reflection on the values and mission of the profession and the way forward with respect to Indigenous Peoples, and to situate nursing education's contributions to a global agenda for social justice, health, and healing (Sullivan et al., 2019). Public health nursing practice also is a core aspect of viable health care, healthy communities, and ecologically just and safe living conditions for all people. These declarations should inspire the vision of the meaning and breadth of how public health nursing is expressed and evolves to serve society-but will they?

Since 2018, the International Council of Nurses (ICN) has been an active leader in the Nursing Now Campaign in partnership with the WHO to harness the global power of nurses in a social justice agenda for health (ICN, 2020). One of the most important advocacy initiatives is for universal health coverage - access to health services and universal basic income; there is a call for nurses to lead campaigns and influence political agendas for these social justice initiatives. As previously discussed, advocacy and health equity are core public health nursing standards (Community Health Nurses of Canada, 2019), and we must ask how or if we are preparing nurses for effective advocacy roles.

Further, we need to attend to the question of scope in nursing education. Breadth and depth of knowledge for practice in public health was in 1919 an integral component of a university education for nurses. Today, nursing education policy issues garnering attention and support are situated in acknowledging the scope of practice within the nursing family, the rise of the nurse practitioner role in primary care, the preparation of the new graduates for "specialty nursing" and the endorsement of interprofessional-team-based care as the cornerstone of health systems (Duncan et al., 2014; Nelson et al., 2014). As health policy agendas are taken up in nursing education programs, it is timely to question how nursing education responds to or anticipates challenges within the discipline and the profession - namely, if scope of practice is interpreted as the integration of knowledge and practice or as a task orientation to care (ICN, 2013). We must also ask, to what extent are nursing's distinct contributions to health teams valued and taken up within interprofessional and interdisciplinary approaches? Despite vision and advancements, we argue that unexamined tensions remain in the delineation and acceptance of a university-level education for nurses that pose significant challenges today.

Nursing's collective voice is essential to making the difference in nursing education and ensure that changes in education are visionary as opposed to reactive. We must ask, how does nursing actualize its collective voice and power? How to best strengthen and critique nursing's thought collectives today? The WHO (2020) has called upon the world's nurses to expand education, lead the development of new delivery models, and advocate for justice and health equity. A powerful collective voice is therefore required of all of us, as it was in 1919; it is time to reflect on the current state of nursing organizations at provincial, territorial, and national levels.

Decades after the completion of her role at UBC, Johns (1965) reflected on "the experiment" in a letter to her successor in the role of director of the UBC School of Nursing. In particular, she acknowledged the resilience of the students and how they were able to rise to the occasion of immense responsibilities. Acknowledging the strengths and vision of nursing students 
is another way forward and a prime responsibility of nursing education to affirm intergenerational contributions to a 21 st-century health system.

Johns (1930) reflected on the sense of values required to stay with the commitment to a university education for nurses, and the courage required to sustain it amid tensions between the ideals of practice and the ideals of education. We are inspired by how Johns was eloquent in her communication of vision and rigorous in her attention to the imperative of an academic education - in her writings and her dealings with governments, she was a clear advocate for the importance of university nursing education. Johns's commitment inspires the vision that a university education for entry-level practice (BSN) is needed to provide clarity of purpose and direction for the discipline and profession of today. Years have passed since the last inquiry into the state of nursing education in Canada and it is therefore timely to consider how such a process may serve our purpose and mandate today. The value of such a process to inform the vision of a baccalaureate education for nurses will be determined by the rigour and purpose of the questions asked.

Johns and others who followed inspire the need for us to engage in critical inquiry and a research agenda to determine the process and outcomes of "the experiment" that began in 1919 and continues in the 21st century. Against the backdrop of the last century and the current lessons of how nursing education and public health nursing have capacities to address the COVID-19 emergency, we contend that nursing must project its destiny and contributions to establish a progressive and indisputable future agenda for nursing education. This agenda must reaffirm and strengthen an academic preparation for registered nurses, including a robust preparation in public health nursing and primary health care, with as much conviction and force as they did in 1919. Finally, we must follow Johns's example of eloquent and influential communications that counter the invisibility of nurses in current discussions of the future state of their practice, profession, and the public health issues of our time. We should ask ourselves the same question today as she did in the closing of her signature address in 1919:

Now what are we as nurses going to do about it? (pp. 123-124)

\section{Acknowledgments}

The authors acknowledge the two reviewers of this paper for their excellent insights. Further, we acknowledge the many excellent works on the history of nursing education of other authors upon whose scholarship we were able to build and who have contributed a strong foundation to the understandings of nursing education in Canada and globally. 


\section{References}

Aiken, L. H. (2014). Baccalaureate nurses and hospital outcomes: More evidence. Medical Care, 52(10), 861-863. https://doi.org/ 10.1097/MLR.0000000000000222

Aiken, L. H., Sloane, D., Griffiths, P., Rafferty, A. M., Bruyneel, L., McHugh, M., Maier, C. B., Moreno-Casbas, T., Ball, J. E., Ausserhofer, D., \& Sermeus, W. (2017). Nursing skill mix in European hospitals: Cross-sectional study of the association with mortality, patient ratings, and quality of care. BMJ Quality \& Safety, 26, 559-568. https://https://doi.org/10.1136/bmjqs-2016-005567

Armstrong-Reid, S. E. (2014). Lyle Creelman: The frontiers of global nursing. University of Toronto Press.

Baer, E. (1984). Nursing's divided house-A historical view. Nursing Research, 34(1), 32-38.

Boschma, G. (2005). Nursing at the University of Calgary, 1969-2004: Faculty of Nursing on the move. University of Calgary Press.

British Columbia College of Nursing Professionals. (2020). Harmonized standards and resources. https://www.bccnp.ca/Standards/all_nurses/Pages/Default.aspx

Brush, B. L., Lynaugh, J. E., Boschma, G., Rafferty, A. M., Stuart, M., \& Tomes, N. J. (1999). Nurses of all nations: A history of the International Council of Nurses, 1899-1999. Lippincott/Raven.

Butterfield, P. (2017). Thinking upstream: A 25-year retrospective and conceptual model aimed at reducing health inequities. Advances in Nursing Science, 40(1), 2-11. https://doi.org/10.1097/ANS.0000000000000161

Community Health Nurses of Canada. (2019). Canadian community health nursing professional practice model and standards of practice. https://www.chnc.ca/en/standards-of-practice

Caputo, S. A. (2016). The development of practical nursing in British Columbia: A social historical perspective, 1940-1980 [Unpublished master's thesis]. University of British Columbia.

Canadian Association of Schools of Nursing. (2012). Ties that bind: The evolution of education for professional nursing in Canada from the 17th to the $21^{\text {st }}$ century. https://www.casn.ca/wp-content/uploads/2016/12/History.pdf

Canadian Association of Schools of Nursing. (2015). National nursing education framework. https://www.casn.ca/wp-content/uploads/2014/12/Framwork-FINAL-SB-Nov-3020151.pdf

Duncan, S. (2016). The history of community health nursing in Canada. In L. Stamler, L. Yiu, \& A. Dosani (Eds.), Community health nursing: A Canadian perspective, (4th ed., chapter 1). Pearson.

Duncan, S. M., Leipert, B. D., \& Mill, J. E. (1999). "Nurses as health evangelists"? The evolution of public health nursing in Canada, 1918-1939. Advances in Nursing Science, 22(1), 40-51. 
Duncan, S. M., Rodney, P. A., \& Thorne, S. (2014). Forging a strong nursing future: Insights from Canada. Journal of Research in Nursing, 19, 621-633. https://doi.org/10.1177/1744987114559063

Duncan, S. M., \& Whyte, N. B. (2018). British Columbia's one nursing regulator: A critical commentary on the amalgamation process. Nursing Leadership, 31(3), 24-33. https://doi.org/10.12927/cjnl.2018.25680

Emory, F. H. M. (1953). Public health nursing in Canada: Principles and practice. MacMillan.

Falk-Rafael, A. R. (1999). The politics of health promotion: Influences on public health promoting nursing practice, Ontario, Canada from Nightingale to the Nineties. Advances in Nursing Science, 22(1), 23-39.

Grypma, S. (2003). Profile of a leader: Unearthing Ethel Johns's "buried” commitment to racial equality, 1925. Nursing Leadership, 16(4), 39-47.

Grypma, S. (2017). Historically informed nursing: The untapped potential of history in nursing education. Quality Advancement in Nursing Education-Avancées en formation infirmière, 3(1), Article 2. https://doi.org/10.17483/2368-6669.1099

Grypma, S. (2019, November 27). Why Canada needs a chief nursing officer now. Nurses and Nurse Practitioners Association of British Columbia. https://www.nnpbc.com/whycanada-needs-a-chief-nursing-officer-now/

Hall, E. (1964). Royal commission on health services. Government of Canada.

Hamilton, D. (1994). Constructing the mind of nursing. Nursing History Review, 2, 3-28.

International Council of Nurses. (2013). Position on scope of practice. https://www.icn.ch/sites/default/files/inline-files/B07_Scope_Nsg_Practice.pdf

International Council of Nurses. (2020, June 25). International nursing expert joins ICN to oversee transition of Nursing Now campaign into ICN's core work. https://www.icn.ch/news/international-nursing-expert-joins-icn-oversee-transitionnursing-now-campaign-icns-core-work

Johns, E. (1919). Address to staff and pupils of the Training School and members of the Training School Committee of the Vancouver General Hospital. Open Collection, UBC Library and Archives. https://open.library.ubc.ca/collections/historyofnursinginpacificcanada/etheljohns/items/1 .0051553\#p6z-7r0f:Ethel\%20johns\%20fonds

Johns, E. (1930, June 30). A sense of values. Speech given at the 1930 biennial meeting of the Canadian Nurses Association. Published in The Canadian Nurse, 26(September). Open Collection, UBC Library and Archives. https://open.library.ubc.ca/collections/historyofnursinginpacificcanada/etheljohns/items/1 .0051562\#p4z-7r0f:

Johns, E. (1936). [Letter to unknown recipient]. Re: UBC Dept. of Nursing, c. 1936. Open Collection, UBC Library and Archives. https://open.library.ubc.ca/collections/historyofnursinginpacificcanada/etheljohns/items/1 $.0051545 \# \mathrm{p} 4 \mathrm{z}-6 \mathrm{r} 0 \mathrm{f}$ : 
Johns, E. (1965, September 16). [Letter to Dr. Muriel Uprichard]. Open Collection, UBC Library and Archives.

https://open.library.ubc.ca/collections/historyofnursinginpacificcanada/etheljohns/items/1 $.0051560 \# p 0 z-7 \mathrm{r} 0 \mathrm{f}$ :

Kirk, M. (2020). When it is no longer your call: Managing the eroding public health nursing role [Unpublished doctoral dissertation]. University of Victoria School of Nursing.

Lapeyre, J., \& Nelson, S. (2010). The "Old Internationals": Canadian nurses in an international nursing community. Nursing Leadership, 23(4), 33-44. https://doi.org/10.12927/cjnl.2011.22141

MacKinnon, K., Butcher, D. L., \& Bruce, A. (2018). Working to full scope: The reorganization of nursing work in two Canadian community hospitals. Global Qualitative Nursing Research, 5, 1-14. https://doi.org/10.1177/2333393617753905

Mansell, D. J. (2004). Forging the future: A history of nursing in Canada. Thomas Press.

McKay, M. (2009). Public health nursing in early 20th century Canada. Canadian Journal of Public Health, 100(4), 249-250.

McPherson, K. (1997). The lessons of Ethel Johns. Registered Nurse Journal, 9(5), 11-13.

Mussallem, H. K. (1960). Spotlight on nursing education: The report of the pilot project for the evaluation of Schools of Nursing in Canada. Canadian Nurses Association.

Needleman, J., Jinjing, S., Sheng, L., Larson, E. E., \& Stone, P. W. (2020). Association of registered nurse and nursing support staffing with inpatient hospital mortality. BMJ Quality \& Safety, 29, 10-18. https://doi.org/10.1136/bmjqs-2018-009219

Nelson, S., Turnbull, J., Bainbridge, L., Caulfield, T., Hudon, G., Kendel, D., Mowat, D., Nasmith, L., Postl, B., Shamian, J., \& Sketris, I. (2014). Optimizing scopes of practice: New models for a new health care system. Canadian Academy of Health Sciences.

Parks Canada. (2009). Johns, Ethel (1879-1968), National Historic Person. Directory of Federal Heritage, Designations. https://www.pc.gc.ca/apps/dfhd/page_nhs_eng.aspx?id=12544

Ross Kerr, J. C. (1995). Visions realized and dreams dashed: Helen Penhale and the first basic integrated baccalaureate program in nursing in the West, at the University of Alberta 1952-1956. Canadian Journal of Nursing Research, 27(3), 39-63.

Sanders, T., O’Mahony, J., Duncan, S., Mahara, S., Pitman, V., Ringstad, K., \& Weatherman, K. (2019). Opening the doors for school health-An exploration of public health nurses' capacities to engage in comprehensive school health programs. Public Health Nursing, 36(3), 348-356. https://doi.org/10.1111/phn.12607

Scaia, M. (2017). Becoming a nurse in Vancouver and Calgary: Women, work, motherhood, 1958 to 1976. BC Studies, 194, 91-118. https://doi.org/10.14288/bcs.v0i194.186234

Stewart, L. (1990). "It's up to you”: Women at UBC in the early years. UBC Press; UBC Academic Women's Association.

Street, M. (1973). Watch-fires on the mountains: The life and writings of Ethel Johns. University of Toronto Press. 
Sullivan, G., Bell, J., Haimour, M., \& Richter, S. (2019). Is university nursing education in Canada taking the lead in a world focused on sustainable development? Quality Advancement in Nursing Education-Avancées en formation infirmière, 5(2), Article 2. https://doi.org/10.17483/2368-6669.1177

Toman, C. (2005). "Body work," medical technology, and hospital nursing practice. In C. Bates, D. Dodd, \& N. Rousseau (Eds.), On all frontiers: Four centuries of Canadian nursing (pp. 89-106). Ottawa University Press.

Truth and Reconciliation Commission of Canada. (2015). Calls to action. http://trc.ca/assets/pdf/Calls_to_Action_English2.pdf

Tunis, B. L. (1966). In caps and gowns: The story of the school of graduate nurses at McGill University, 1920-1964. McGill University Press.

Twohig, P. (2018). The second "Great Transformation": Renegotiating nursing practice in Ontario, 1945-70. Canadian Historical Review, 99(2), 169-195. https://doi.org/10.3138/chr.99.2.01

United Nations. (2007). Declaration on the rights of Indigenous Peoples. https://www.un.org/development/desa/indigenouspeoples/wpcontent/uploads/sites/19/2018/11/UNDRIP_E_web.pdf

United Nations. (2015). Transforming our world: The 2030 agenda for sustainable development. https://sustainabledevelopment.un.org/content/documents/21252030\%20Agenda\%20for $\% 20$ Sustainable\%20Development $\% 20 \mathrm{web} . \mathrm{pdf}$

Weir, G. (1932). Survey of nursing education in Canada. Toronto: University of Toronto Press.

World Health Organization. (2020). State of the world's nursing report 2020: Investing in education, jobs and leadership. https://www.who.int/publications/i/item/9789240003279

Young, J. (2005). Revisiting the 1925 Johns Report on African-American nurses. Nursing History Review, 13, 77-99.

Zawaduk, C., Duncan, S., Mahara, M. S., Tate, B., Callaghan, D., McCullough, D., Chapman, M., \& Van Neste-Kenny, J. (2014). Mission possible: 25 years of university and college collaboration in baccalaureate nursing education. Journal of Nursing Education, 53(10), 580-588. https://doi.org/10.3928/01484834-20140922-04

Zilm, G., \& Warbinek, E. (1994). Legacy: History of nursing education at the University of British Columbia, 1919-1994. UBC Press 